2016-06-01

\title{
Axial compression buckling of castellated columns at elevated temperatures
}

\author{
Li, Long-yuan
}

http://hdl.handle.net/10026.1/4890

\subsection{2/S0219455417500341}

International Journal of Structural Stability and Dynamics

World Scientific Pub Co Pte Lt

All content in PEARL is protected by copyright law. Author manuscripts are made available in accordance with publisher policies. Please cite only the published version using the details provided on the item record or document. In the absence of an open licence (e.g. Creative Commons), permissions for further reuse of content should be sought from the publisher or author. 
Submitted 11 March 2016

Accepted 11 April 2016

Published 1 June 2016 (online) (DOI: 10.1142/S0219455417500341)

Citation: International Journal of Structural Stability and Dynamics 2017, 17(3)

\section{Axial compression buckling of castellated columns at elevated temperatures}

Jin-song Lei ${ }^{\mathrm{a}}$, Wei-bin Yuan ${ }^{\mathrm{b}}$, Long-yuan $\mathrm{Li}^{\mathrm{c}}$

a) College of Civil Engineering and Architecture, Southwest University of Science and Technology, Mianyang 621010, China

b) College of Civil Engineering and Architecture, Zhejiang University of Technology, Hangzhou, China (yuanwb@zjut.edu.cn, corresponding author)

c) School of Marine Science and Engineering, University of Plymouth, Plymouth PL4 8AA, UK

Abstract - In this paper, the axial compression buckling problem of castellated columns about major axis when exposed to a fire is investigated. An analytical formula for calculating the critical buckling load of castellated columns is derived, which considers not only the shear effect of web openings but also the non-uniform cross-section temperature distribution due to non-symmetric fire exposure. The results show that, for the same average temperature, the critical buckling load of a castellated column with non-uniform temperature distribution is smaller than that of a castellated column with uniform temperature distribution. The web shear effect caused due to web openings can significantly reduce the critical buckling load of the castellated column, particularly for the columns with shorter lengths or wider flanges. However, the change of the shear effect on the critical load with different temperature distributions is very small and can be generally ignored.

Keywords: Buckling, compression, castellated column, shear effect, elevated temperature, fire.

\section{Introduction}

Castellated beams and columns have been widely used in buildings to support roof and floor loading. ${ }^{1,2}$ A castellated beam or column is fabricated from a standard universal beam or column by cutting the web on a half hexagonal line down the centre of the beam. The two halves are moved across by a half unit of spacing and then re-joined by welding. The main benefit of using the castellated beam or column is to increase its flexural capacity and buckling resistance about its major axis. However, because of the openings in the web, the castellated beam and column have weak shear rigidity which can affect their bending and buckling behaviour.

There are numerous research works on castellated beams in literature, particularly on the lateral-torsional buckling, ${ }^{3-7}$ distortional buckling, ${ }^{8}$ failure caused by buckling mode interactions, ${ }^{9}$ and ultimate load carrying capacity. ${ }^{10-13}$ In contrast, there are limited studies on castellated columns. El-Sawy et al. ${ }^{14}$ investigated the influence of shear deformations due to web openings on the buckling capacity of castellated columns when they buckle about the cross-section major axis. By using the finite element analysis method they evaluated the 
equivalent slenderness ratio of castellated columns for the practical range of geometric dimensions and boundary conditions to characterize the compressive response of such columns. Yuan et al. ${ }^{15}$ developed an analytical formula for calculating the critical buckling load of castellated columns when subjected to an axially compressed load, which includes the shear effect of web openings. Their study showed that the inclusion of web shear deformations significantly reduces the buckling resistance of castellated columns. Neglecting the web shear deformations could overestimate the critical buckling load by up to $25 \%$, even if a reduced second moment of area is used.

Fire safety of structures used in buildings is a key issue in building design. The performance of castellated beams under fire conditions is investigated only recently. Wang et al. ${ }^{16}$ investigated the large deflection and its corresponding catenary action behaviour of restrained castellated beams in fire by using the finite element method. Ellobody and Young ${ }^{17}$ developed a three-dimensional nonlinear finite element analysis model and discussed the nonlinear analysis and design of unprotected composite castellated and noncastellated steel beams with profiled steel sheeting at elevated temperatures. Their results showed that, the strength of steel beam has a considerable effect on the behaviour and failure modes of the composite beams which could change the failure mode of the composite beams in fire, and the fire resistances of the unprotected composite castellated and noncastellated steel beams could be below 30 min when heated using the standard fire curve. It is well-known that not only the strength but also the Young's modulus of materials will reduce at elevated temperatures. The former will reduce the ultimate load carrying capacity of the structural members, while the latter will affect the stiffness of structural members and thus reduce the buckling resistance of the members. In this paper, the axial compression buckling problem of castellated columns about major axis when exposed to a fire is investigated. An analytical formula for calculating the critical buckling load of castellated columns is derived, which considers not only the shear effect of web openings but also the non-uniform cross-section temperature distribution due to non-symmetric fire exposure.

\section{Pre-buckling analysis of castellated columns exposed to a fire}

Consider a castellated column that is used in the external wall, in which the column can be bent about its major axis but is restrained in its lateral direction. When there is a fire in the inside of the building the castellated column is exposed to a fire on its one side. During the fire the heat will be transferred from the fire into the column, which causes the column to have a non-uniform temperature distribution on its cross-section. Consequently, the material properties which depend on the temperature will also not be uniform in the cross-section. Using the assumption of small displacements, the following equilibrium equation for the axial force can be established,

$\int_{A} E(\varepsilon-\alpha \Delta T) d A=-P$

where $E$ is the Young's modulus, $\varepsilon$ is the axial strain, $\alpha$ is the thermal coefficient of expansion, $\Delta T$ is the increase of temperature, $A$ is the cross-section area, and $P$ is the axially compressive load. For the convenience of calculation, the cross-section of the castellated column is now decomposed into two tee-sections and one mid-part of the web (see Fig. 1). Because of the discontinuity of the mid-part of the web, the compressive load is assumed to be taken only by the two tee sections, that is, 
$\int_{A_{1}} E(\varepsilon-\alpha \Delta T) d A+\int_{A_{2}} E(\varepsilon-\alpha \Delta T) d A=-P$

where $A_{1}$ and $A_{2}$ are the areas of the two tee sections. Since the heat is transferred from one flange to another through the web it is reasonable to assume that the temperature is uniformly distributed in each tee section although the two tee sections may have different temperatures at the same time. ${ }^{18}$ Assume that the compressive load is applied using a displacement controlled method. Then, Eq.(2) can be simplified as follows,

$$
E_{1} A_{1}\left(\varepsilon-\alpha \Delta T_{1}\right)+E_{2} A_{2}\left(\varepsilon-\alpha \Delta T_{2}\right)=-P
$$

where $E_{1}$ and $E_{2}$ are the Young's moduli of the two tee sections, $\Delta T_{1}$ and $\Delta T_{2}$ are the increases of temperatures in the two tee sections, respectively. Solve for the axial strain from Eq.(3), yielding,

$$
\varepsilon=\frac{\alpha\left(E_{1} A_{1} \Delta T_{1}+E_{2} A_{2} \Delta T_{2}\right)-P}{E_{1} A_{1}+E_{2} A_{2}}
$$

The equivalent compressive loads in the two tee sections in the pre-buckling stage thus can be expressed as follows,

$$
\begin{aligned}
& P_{1}=-E_{1} A_{1}\left(\varepsilon-\alpha \Delta T_{1}\right)=\frac{E_{1} A_{1}\left[P-\alpha E_{2} A_{2}\left(\Delta T_{2}-\Delta T_{1}\right)\right]}{E_{1} A_{1}+E_{2} A_{2}} \\
& P_{2}=-E_{2} A_{2}\left(\varepsilon-\alpha \Delta T_{2}\right)=\frac{E_{2} A_{2}\left[P+\alpha E_{1} A_{1}\left(\Delta T_{2}-\Delta T_{1}\right)\right]}{E_{1} A_{1}+E_{2} A_{2}}
\end{aligned}
$$

where $P_{1}$ and $P_{2}$ are the equivalent axially compressive loads applied at the centroids of the two tee sections, respectively. It is obvious that if $\Delta T_{1}=\Delta T_{2}$, then $E_{1} A_{1}=E_{2} A_{2}$ and $P_{1}=P_{2}=$ $P / 2$, in which case the buckling of the castellated column can be dealt using the Euler buckling method. ${ }^{15}$ However, when $\Delta T_{1} \neq \Delta T_{2}, P_{1} \neq P_{2}$ and in this case the castellated column is subjected to a combined action of compression and bending and its buckling is different from the traditional Euler buckling of columns at ambient temperature.

\section{Buckling analysis of castellated columns exposed to a fire}

The heated castellated column under the action of an axial compression load may buckle. In order to analyse the buckling of the castellated column under the combined action of compression and bending, the bending theory of sandwich beams ${ }^{19-21}$ is used herein, in which the two tee sections are assumed to deform according to Bernoulli's hypothesis and the midpart of the web behaves as a shear wall to take shear force only. Let $\left(u_{1}, w\right)$ and $\left(u_{2}, w\right)$ be the axial and transverse components of the buckling displacements at the centroid points of the two tee sections (see Fig.2), the strain energy of the two tee sections due to the buckling of the column can be expressed as follows, ${ }^{15,22-26}$

$$
U_{1}=\frac{1}{2} \int_{o}^{l}\left[E_{1} A_{1}\left(\frac{d u_{1}}{d x}\right)^{2}+E_{1} I_{1}\left(\frac{d^{2} v}{d x^{2}}\right)^{2}\right] d x
$$


$U_{2}=\frac{1}{2} \int_{o}^{l}\left[E_{2} A_{2}\left(\frac{d u_{2}}{d x}\right)^{2}+E_{2} I_{2}\left(\frac{d^{2} v}{d x^{2}}\right)^{2}\right] d x$

where $I_{1}$ and $I_{2}$ are the second moments of areas of the two tee sections about their own centroid axes, and $l$ is the length of the column. The average shear strain of the mid-part of the web is expressed as follows,

$\gamma_{x y}=\frac{e}{a} \frac{d v}{d x}-\frac{u_{1}-u_{2}}{2 a}$

where $a$ is the half depth of hexagons, and $e$ is the half of the distance between the centroids of the two tee sections. The shear strain energy of the mid-part of the web thus is expressed as follows, ${ }^{15}$

$U_{3}=\frac{a t_{w}}{4} \int_{o}^{l} G \gamma_{x y}^{2} d x=\frac{t_{w} e^{2}\left(E_{1}+E_{2}\right)}{16(1+v) a} \int_{o}^{l}\left(\frac{d v}{d x}-\frac{u_{1}-u_{2}}{2 e}\right)^{2} d x$

where $t_{w}$ is the web thickness, $G$ is the shear modulus, and $v$ is the Passion's ratio. The calculation of the shear strain energy used by Eq.(10) has been proved to be appropriate in the buckling and vibration analyses of castellated beams. ${ }^{15,25,26}$ The potential changes of the equivalent loads in the two tee sections due to the axial and transverse components of the buckling displacements can be expressed as follows,

$$
\begin{aligned}
& W_{1}=-P_{1} \int_{o}^{l}\left[\frac{d u_{1}}{d x}-\frac{1}{2}\left(\frac{d v}{d x}\right)^{2}\right] d x \\
& W_{2}=-P_{2} \int_{o}^{l}\left[\frac{d u_{2}}{d x}-\frac{1}{2}\left(\frac{d v}{d x}\right)^{2}\right] d x
\end{aligned}
$$

Assume that the displacement components of the column when it buckles can be described as follows,

$$
\begin{aligned}
& u_{1}(x)=C_{1} \cos \frac{\pi x}{l} \\
& u_{2}(x)=C_{2} \cos \frac{\pi x}{l} \\
& v(x)=C_{3} \sin \frac{\pi x}{l}
\end{aligned}
$$

where $C_{1}, C_{2}$ and $C_{3}$ are the constants to be determined. It is obvious that the displacement functions assumed in Eqs.(13)-(15) satisfy the simply support boundary conditions, that is $v=$ $d v^{2} / d x_{2}=0$, and $d u_{1} / d x=d u_{2} / d x=0$ at $x=0$ and $x=l$. The condition when the buckling occurs is that the total potential of the system has a stationary condition with respect to the constants $C_{1}, C_{2}$ and $C_{3}$, that is,

$$
\begin{aligned}
& \frac{\partial \Pi}{\partial C_{1}}=\frac{\partial}{\partial C_{1}}\left(U_{1}+U_{2}+U_{3}-W_{1}-W_{2}\right)=0 \\
& \frac{\partial \Pi}{\partial C_{2}}=\frac{\partial}{\partial C_{2}}\left(U_{1}+U_{2}+U_{3}-W_{1}-W_{2}\right)=0 \\
& \frac{\partial \Pi}{\partial C_{3}}=\frac{\partial}{\partial C_{3}}\left(U_{1}+U_{2}+U_{3}-W_{1}-W_{2}\right)=0
\end{aligned}
$$


Substituting Eqs. (13)-(15) into (7)-(12) and then into (16)-(18), it yields

$$
\left[\begin{array}{lll}
A_{11} & A_{12} & A_{13} \\
A_{21} & A_{22} & A_{23} \\
A_{31} & A_{32} & A_{33}
\end{array}\right]\left\{\begin{array}{l}
C_{1} \\
C_{2} \\
C_{3}
\end{array}\right\}=P_{c r}\left[\begin{array}{lll}
B_{11} & B_{12} & B_{13} \\
B_{21} & B_{22} & B_{23} \\
B_{31} & B_{32} & B_{33}
\end{array}\right]\left\{\begin{array}{l}
C_{1} \\
C_{2} \\
C_{3}
\end{array}\right\}
$$

in which

$$
\begin{aligned}
& A_{11}=\frac{\partial^{2} U}{\partial C_{1}^{2}}=E_{1} A_{1}\left(\frac{\pi}{l}\right)^{2}+\frac{t_{w}\left(E_{1}+E_{2}\right)}{32(1+v) a} \\
& A_{12}=A_{21}=\frac{\partial^{2} U}{\partial C_{1} \partial C_{2}}=-\frac{t_{w}\left(E_{1}+E_{2}\right)}{32(1+v) a} \\
& A_{13}=A_{31}=\frac{\partial^{2} U}{\partial C_{1} \partial C_{3}}=-\frac{t_{w} e\left(E_{1}+E_{2}\right) \pi}{16(1+v) a l} \\
& A_{22}=\frac{\partial^{2} U}{\partial C_{2}^{2}}=E_{2} A_{2}\left(\frac{\pi}{l}\right)^{2}+\frac{t_{w}\left(E_{1}+E_{2}\right)}{32(1+v) a} \\
& A_{23}=A_{32}=\frac{\partial^{2} U}{\partial C_{2} \partial C_{3}}=\frac{t_{w} e\left(E_{1}+E_{2}\right) \pi}{16(1+v) a l} \\
& A_{33}=\frac{\partial^{2} U}{\partial C_{3}^{2}}=E_{1} I_{1}\left(\frac{\pi}{l}\right)^{4}+E_{2} I_{2}\left(\frac{\pi}{l}\right)^{4}+\frac{t_{w} e^{2}\left(E_{1}+E_{2}\right)}{8(1+v) a}\left(\frac{\pi}{l}\right)^{2} \\
& B_{11}=\frac{\partial^{2} W}{\partial C_{1}^{2}}=0 \\
& B_{12}=B_{21}=\frac{\partial^{2} W}{\partial C_{1} \partial C_{2}}=0 \\
& B_{13}=B_{31}=\frac{\partial^{2} W}{\partial C_{1} \partial C_{3}}=0 \\
& B_{33}=\frac{\partial^{2} W}{\partial C_{3}^{2}}=\left(P_{1}+P_{2}\right)\left(\frac{\pi}{l}\right)^{2} \\
& B_{23}=B_{32}=\frac{\partial^{2} W}{\partial C_{2} \partial C_{3}}=0 \\
& B_{2}
\end{aligned}
$$

where $U=U_{1}+U_{2}+U_{3}$ and $W=W_{1}+W_{2}$. Eq. (19) is an eigenvalue equation from which the critical buckling load $P_{c r}$ can be obtained, which is expressed as follows,

$$
P_{c r}=\left(E_{1} I_{1}+E_{2} I_{2}\right)\left(\frac{\pi}{l}\right)^{2}+\frac{t_{w} e^{2}\left(E_{1}+E_{2}\right)}{8(1+v) a}-\frac{\left[\frac{t_{w} e\left(E_{1}+E_{2}\right)}{16(1+v) a}\right]^{2}}{\frac{E_{1} A_{1} E_{2} A_{2}}{E_{1} A_{1}+E_{2} A_{2}}\left(\frac{\pi}{l}\right)^{2}+\frac{t_{w}\left(E_{1}+E_{2}\right)}{32(1+v) a}}
$$

Note that for castellated columns, $A_{1}=A_{2}=A_{\text {tee }}$ and $I_{1}=I_{2}=I_{\text {tee }}$. Thus, Eq.(32) can be further simplified as follows, 


$$
P_{c r}=\left(E_{1}+E_{2}\right) I_{t e e}\left(\frac{\pi}{l}\right)^{2}+\frac{\frac{4 e^{2} E_{1} E_{2} A_{t e e}}{E_{1}+E_{2}}\left(\frac{\pi}{l}\right)^{2}}{1+\frac{32(1+v) a E_{1} E_{2} A_{t e e}}{\left(E_{1}+E_{2}\right)^{2} t_{w}}\left(\frac{\pi}{l}\right)^{2}}
$$

Eq.(33) gives the critical buckling load of the castellated column when its one side is exposed to a fire. The influence of the fire on the column buckling is taken into account by the material properties, i.e., the reduction of Young's modulus. It is obvious that if $E_{1}=E_{2}=E_{o}$ where $E_{o}$ is the Young's modulus at ambient temperature, then Eq.(32) reduces to that derived by Yuan et al. ${ }^{15}$ Similarly to Yuan et al. formula, the second term in the denumerator of Eq.(33) represents the effect of web shear rigidity on the flexural buckling of the column. If that term is ignored, which corresponds to the case where the web shear rigidity is much greater than the flexural rigidity of the column, then Eq.(33) can be simplified as follows:

$$
P_{c r}=\left(E_{1}+E_{2}\right) I_{t e e}\left(\frac{\pi}{l}\right)^{2}+\frac{4 e^{2} E_{1} E_{2} A_{t e e}}{E_{1}+E_{2}}\left(\frac{\pi}{l}\right)^{2}=\frac{\pi^{2}\left(E_{1}+E_{2}\right)\left(I_{t e e}+e^{2} A_{t e e}\right)}{l^{2}}-\frac{\left(E_{1}-E_{2}\right)^{2} e^{2} A_{t e e}}{E_{1}+E_{2}}\left(\frac{\pi}{l}\right)^{2}
$$

Eq.(34) shows the influence of non-uniform material properties caused by the non-uniform temperature on the critical buckling load of the castellated column when the shear effect is ignored.

\section{Examples}

As examples, two castellated columns, one of which has narrow flanges, the other of which has wide flanges, are considered herein. The half of the distance between the centroids of the two tee sections, the area and the second moment of area of the tee section are calculated as follows,

$$
\begin{aligned}
& e=\frac{b_{f} t_{f}\left(\frac{h_{w}+t_{f}}{2}\right)+t_{w}\left(\frac{h_{w}}{2}-a\right)\left(\frac{h_{w}+2 a}{4}\right)}{b_{f} t_{f}+t_{w}\left(\frac{h_{w}}{2}-a\right)} \\
& A_{\text {tee }}=b_{f} t_{f}+\left(\frac{h_{w}}{2}-a\right) t_{w} \\
& I_{\text {tee }}=\frac{b_{f} t_{f}^{3}}{12}+b_{f} t_{f}\left(\frac{h_{w}+t_{f}}{2}-e\right)^{2}+\frac{t_{w}}{12}\left(\frac{h_{w}}{2}-a\right)^{3}+t_{w}\left(\frac{h_{w}}{2}-a\right)\left(e-\frac{h_{w}+2 a}{4}\right)^{2}
\end{aligned}
$$

Table 1 gives the dimensions and corresponding sectional properties of the two castellated columns discussed herein. The critical buckling loads of the two castellated columns are calculated for three fire scenarios for which the temperatures and material properties are described in Table 2, respectively.

Fig. 3 shows the variation of the dimensionless critical buckling load, $P_{c r, T} / P_{c r, 20}$, with the column length, in which $P_{c r, T}$ is calculated using Eq.(33) with the temperatures defined in Table 2, whereas $P_{c r, 20}$ is calculated using Eq.(33) but using ambient temperature. Thus, the 
plotted result reflects the influence of temperature on the buckling of the column in different fire scenarios. It can be seen from the figure that, although the average temperatures in the three discussed cases are identical, the critical buckling loads of them are different. That is, the larger difference in temperatures between the two tee sections leads to more reduction in the critical buckling load. The worst case is the case one in which the two tee sections have the largest temperature difference. In contrast, in the case three the two tee sections have closer temperatures and thus the reduction of the critical buckling load is almost the same as the reduction of the young's modulus. Comparing the results shown in Fig.3a for the narrow flange column and Fig. $3 b$ for the wide flange column, one can see that the influence of the flange width on the dimensionless critical buckling load, $P_{c r, T} / P_{c r, 20}$, occurs only in the short column with larger temperature difference between its two tee sections.

Fig. 4 shows the variation of the dimensionless critical buckling load, $P_{c r, T} / P_{c r o, T}$, with the column length, in which $P_{c r, T}$ is calculated using Eq.(33) with the temperatures defined in Table 2, whereas $P_{c r o, T}$ is calculated using Eq.(34) also with temperatures defined in Table 2. Thus, the plotted result reflects the influence of web shear deformation on the buckling of the column in different fire scenarios. It can be seen from the figure that the web shear deformation has important influence on the critical buckling load, particularly for the columns with short length for which the critical load can reduce significantly. Also it can be seen from the figure that, the shear effects on the critical load in three different fire scenarios are very close, indicating that the shear effect on the critical load does not much depend on the temperature profile. Comparing the results shown in Fig.4a for the narrow flange column and Fig.4b for the wide flange column, one can see that the wider the flanges in the column, the more reduction in the critical buckling load.

\section{Conclusions}

This paper has presented an analytical solution for analysing the axial compression buckling of castellated columns exposed to elevated temperatures. The analysis is based on the Rayleigh-Ritz method with the total potential energy functional for the flanges and web by taking into account the influence of web shear deformations. The effect of elevated temperatures on the buckling of columns is considered by using temperature-dependent material properties. From the obtained results the following conclusions can be drawn:

(1) For the same average temperature, the critical buckling load of a castellated column with non-uniform temperature distribution will be smaller than that of a castellated column with uniform temperature distribution. The larger difference in temperatures between the two tee sections leads to more reduction in the critical buckling load.

(2) The shear effect caused due to web openings can significantly reduce the critical buckling load of the castellated column, particularly for the columns with shorter lengths or wider flanges. The change of the shear effect on the critical load with varying temperature distribution is very small and can be generally ignored.

\section{References}

1. C. Harper, Design in Steel 4: Castellated \& cellular beams, British Steel, British Steel, Port Talbot, UK, 1991. 
2. P. R. Knowles, Castellated beams. Proceedings of Institution of Civil Engineers: Structural and Building Board, Part 1, Part 1, 90 (1991) 521-536.

3. U. C. Pattanayak and E. Chesson, Lateral instability of castellated beams, AISC Engineering Journal 11(3) (1974) 73-79.

4. D. Nethercot and D. Kerdal, Lateral-torsional buckling of castellated beams, The Structural Engineer 60 (1982) 53-61.

5. A. Mohebkhah, The moment-gradient factor in lateral-torsional buckling on inelastic castellated beams, Journal of Constructional Steel Research 60(10) (2004) 1481-1494.

6. B. Kim, L. Y. Li and A. Edmonds, Analytical solutions of lateral-torsional buckling of castellated beams, International Journal of Structural Stability and Dynamics 16(8) (2016) 1-16 (1550044).

7. H. Showkati, T. G. Ghazijahani, A. Noori and T. Zirakian, Experiments on elastically braced castellated beams, Journal of Constructional Steel Research 77 (2012) 163-172.

8. T. Zirakian and H. Showkati, Distortional buckling of castellated beams, Journal of Constructional Steel Research 62(9) (2006) 863-871.

9. E. Ellobody, Interaction of buckling modes in castellated steel beams, Journal of Constructional Steel Research 67(5) (2011) 814-825.

10. D. Kerdal and D. Nethercot, Failure modes for castellated beams, Journal of Constructional Steel Research 4(4) (1984) 295-315.

11. A. Mohebkhah and H. Showkati, Bracing requirements for inelastic castellated beams, Journal of Constructional Steel Research 61(10) (2005) 1373-1386.

12. S. Gholizadeh, A. Pirmoz and R. Attarnejad, Assessment of load carrying capacity of castellated steel beams by neural networks, Journal of Constructional Steel Research 67(5) (2011) 770-779.

13. M. R. Soltani, A. Bouchaïr and M. Mimoune, Nonlinear FE analysis of the ultimate behaviour of steel castellated beams, Journal of Constructional Steel Research 70 (2012) 101-114.

14. K. El-Sawy, A. Sweedan and M. Martini, Major-axis elastic buckling of axially loaded castellated steel columns, Thin-Walled Structures 47(11) (2009) 1295-1304.

15. W. B. Yuan, B. Kim and L. Y. Li, Buckling of axially loaded castellated steel columns, Journal of Constructional Steel Research 92 (2014) 40-45.

16. P. Wang, N. Ma and X. D. Wang, Numerical studies on large deflection behaviours of restrained castellated steel beams in a fire, Journal of Constructional Steel Research 100 (2014) 136-145.

17. E. Ellobody and B. Young, Nonlinear analysis of composite castellated beams with profiled steel sheeting exposed to different fire conditions, Journal of Constructional Steel Research 113 (2015) 247-260.

18. S. S. Cheng, L. Y. Li and B. Kim, Buckling analysis of partially protected cold-formed steel channel-section columns at elevated temperatures, Fire Safety Journal 72 (2015) 7-15.

19. A. Gjelsvik, Stability of built-up columns. Journal of Engineering Mechanics (ASCE) 117(6) (1991) 1331-1345.

20. Z. P. Bazant, Shear buckling of sandwich, fiber composite and lattice columns, bearings, and helical springs: paradox resolved. Journal of Applied Mechanics 70(1) (2003) 75-83.

21. Z. Vasic, V. Raicevic and S. Jovic, Sandwich beam stability analysis applying bending theory of the sandwich constructions. Mech Autom Control Robot 4(17) (2005) 333-43.

22. S. P. Timoshenko and J. M. Gere, Theory of Elastic Stability (2nd edition), New York, McGraw-Hill Book Company, 1961.

23. C. H. Yoo and S. C. Lee, Stability of structures, principles and applications, Oxford, Elsevier, 2011. 
24. J. K. Chen and L. Y. Li, Elastic axially compressed buckling of battened columns, International Journal of Mechanical Sciences 77 (2013) 1-7.

25. J. K. Chen, B. Kim and L. Y. Li, Analytical approach for transverse vibration analysis of castellated beams, International Journal of Structural Stability and Dynamics 14(3) (2014) 113.

26. J. Z. Gu, Free vibration of castellated beams with web shear and rotary inertia effects, International Journal of Structural Stability and Dynamics 14(6) (2014) 1-10 (1450011).

Table 1 Dimensions and properties of two castellated columns

\begin{tabular}{|l|c|c|}
\hline Parameter & Narrow section & Wide section \\
\hline Web depth, $h_{w}$ & $300 \mathrm{~mm}$ & $300 \mathrm{~mm}$ \\
\hline Web thickness, $t_{w}$ & $8 \mathrm{~mm}$ & $8 \mathrm{~mm}$ \\
\hline Flange width, $b_{f}$ & $150 \mathrm{~mm}$ & $250 \mathrm{~mm}$ \\
\hline Flange thickness, $t_{w}$ & $10 \mathrm{~mm}$ & $10 \mathrm{~mm}$ \\
\hline Half depth of hexagons, $a$ & $100 \mathrm{~mm}$ & $100 \mathrm{~mm}$ \\
\hline Half distance between centroids of tee sections, $e$ & $149 \mathrm{~mm}$ & $151 \mathrm{~mm}$ \\
\hline Length of unit, $6 a / \sqrt{3}$ & $346 \mathrm{~mm}$ & $346 \mathrm{~mm}$ \\
\hline Area of tee section, $A_{\text {tee }}$ & $1900 \mathrm{~mm}^{2}$ & $2900 \mathrm{~mm}^{2}$ \\
\hline Second moment of area of tee section, $I_{\text {tee }}$ & $380040 \mathrm{~mm}^{4}$ & $414510 \mathrm{~mm}^{4}$ \\
\hline
\end{tabular}

Table 2 Temperatures and Young's modulus in two tee sections ( $E_{o}$ is the Young's modulus at ambient temperature)

\begin{tabular}{|l|c|c|c|}
\hline Parameter & Case 1 & Case 2 & Case 3 \\
\hline Temperature, $T_{1}$ & $550{ }^{\circ} \mathrm{C}$ & $450{ }^{\circ} \mathrm{C}$ & $350{ }^{\circ} \mathrm{C}$ \\
\hline Temperature, $T_{2}$ & $100{ }^{\circ} \mathrm{C}$ & $200{ }^{\circ} \mathrm{C}$ & $300{ }^{\circ} \mathrm{C}$ \\
\hline Young's modulus, $E_{1}$ & $0.5 E_{o}$ & $0.6 E_{o}$ & $0.7 E_{o}$ \\
\hline Young's modulus, $E_{2}$ & $E_{o}$ & $0.9 E_{o}$ & $0.8 E_{o}$ \\
\hline
\end{tabular}



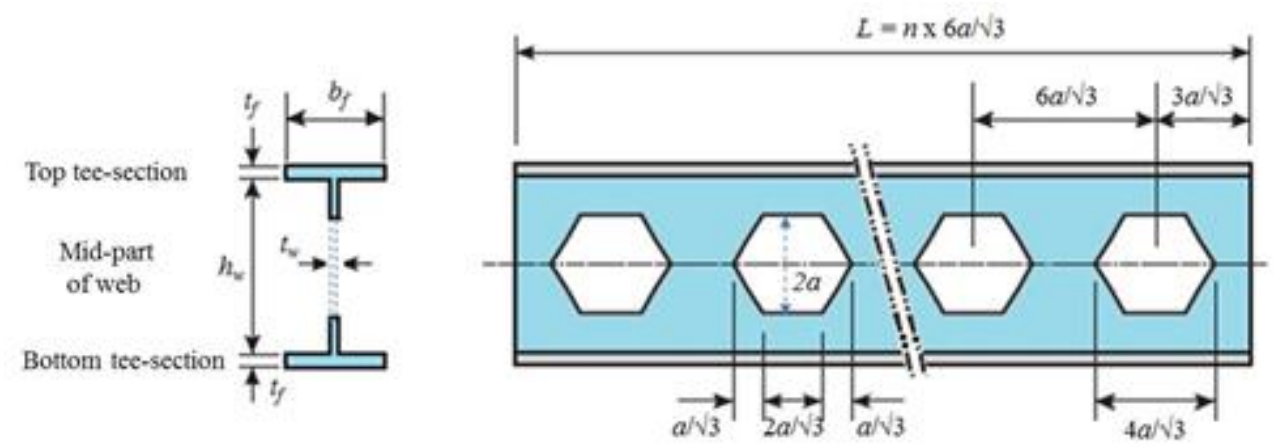

Fig. 1. Notations used in castellated column.

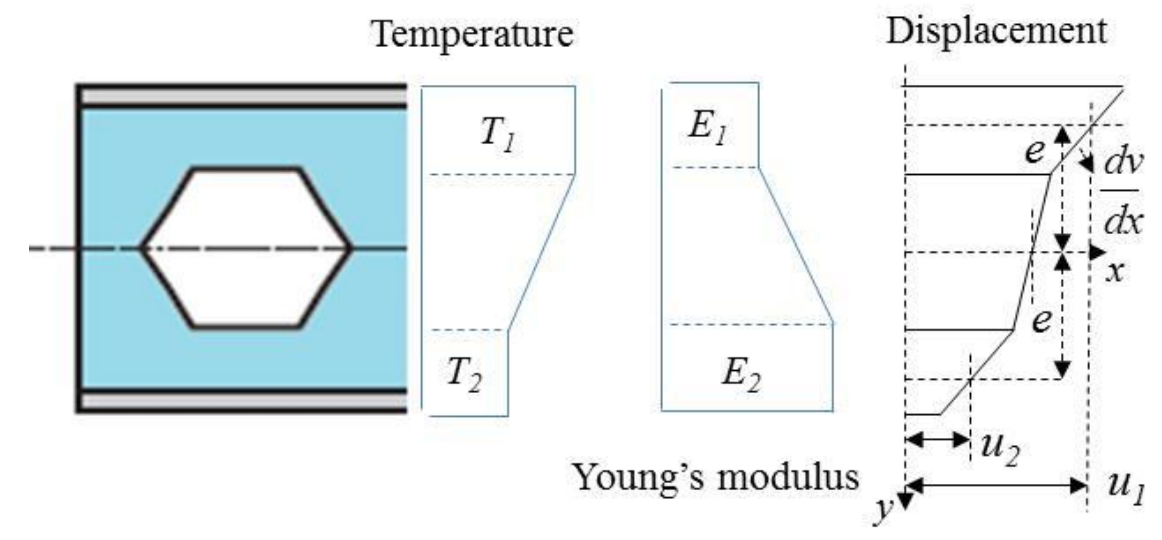

Fig. 2. Definition of temperature, Young's modulus and displacement component in the crosssection. 


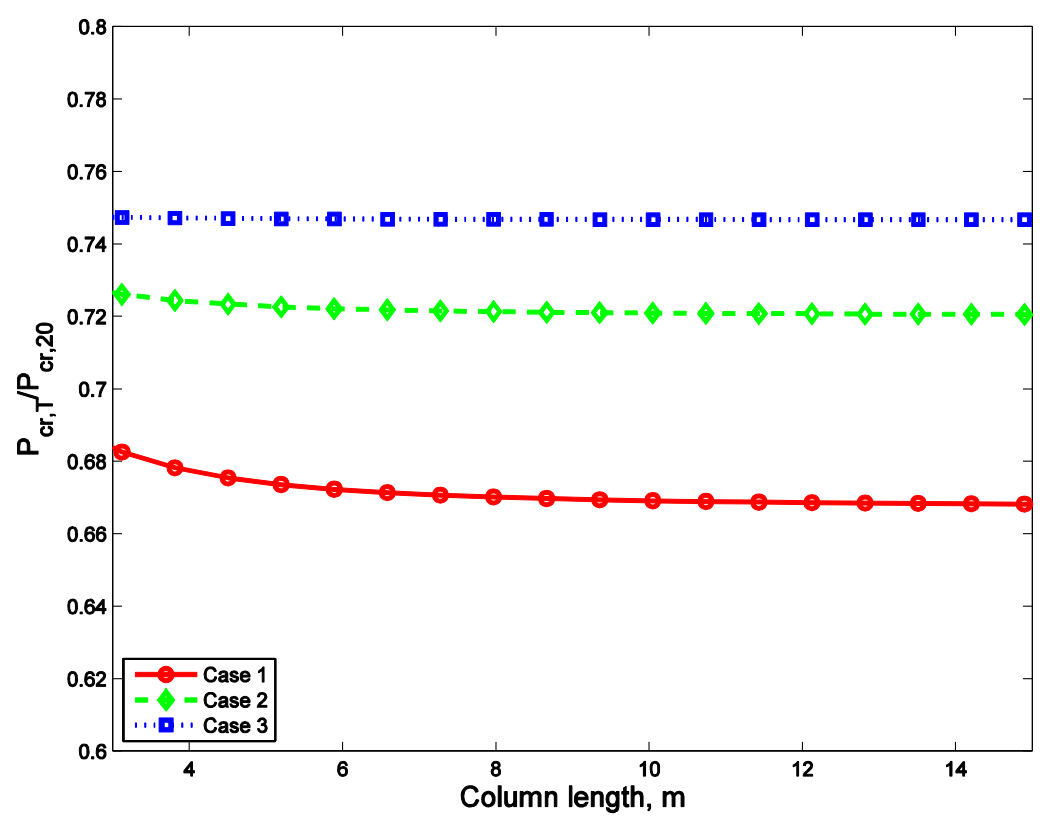

(a)

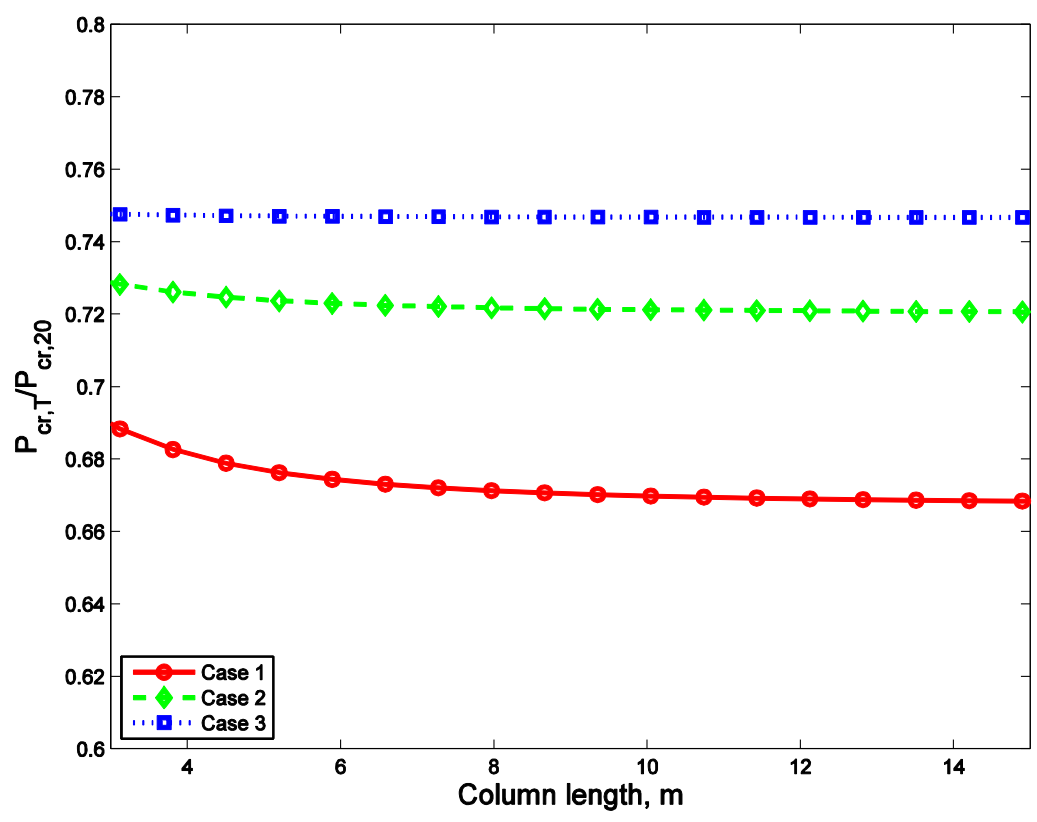

(b)

Fig.3 Variation of critical buckling load with column length. $P_{c r, T}$ is calculated using Eq.(33) with temperatures defined in Table 2, whereas $P_{c r, 20}$ is calculated using Eq.(33) but with ambient temperature. (a) Column with narrow flanges $\left(b_{f}=150 \mathrm{~mm}\right)$ and (b) column with wide flanges $\left(b_{f}=250 \mathrm{~mm}\right)$. 


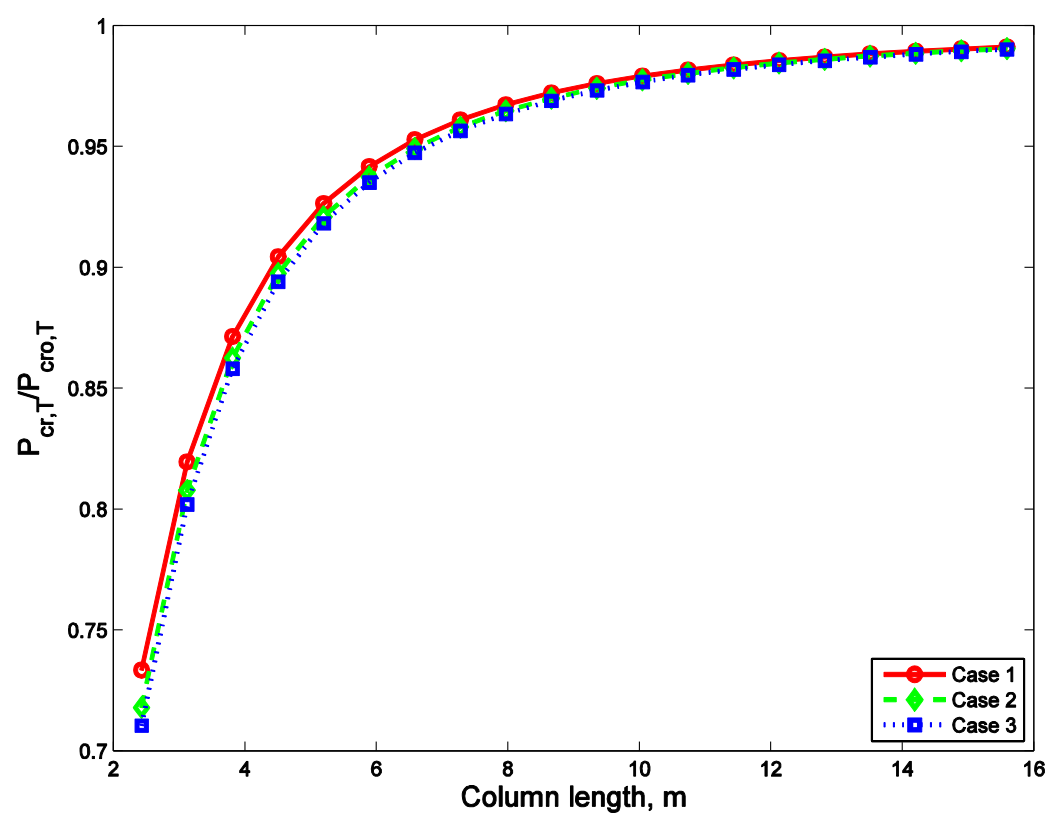

(a)

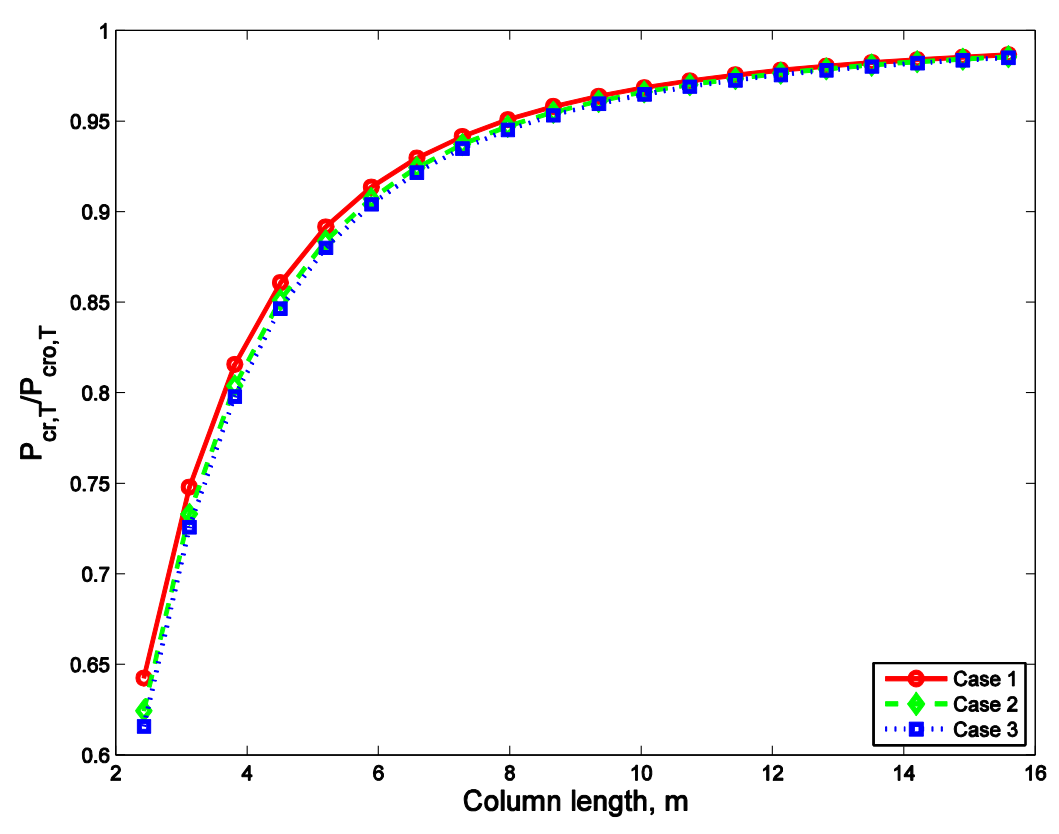

(b)

Fig.4 Variation of critical buckling load with column length. $P_{c r, T}$ and $P_{c r o, T}$ are calculated using Eq.(33) and Eq.(34), both with temperatures defined in Table 2. (a) Column with narrow flanges $\left(b_{f}=150 \mathrm{~mm}\right)$ and $(b)$ column with wide flanges $\left(b_{f}=250 \mathrm{~mm}\right)$. 